only one optical antipode enters into reaction, then the quantities of organic phosphorus necessary to accomplish the same amount of esterification are approximately the same. Thereby, the velocity of the rearrangement of the glyceric aldehyde phosphoric acid is greater than that of hexose di-phosphoric acid, while on the other hand the system glucose plus hexose di-phosphate reacts somewhat more rapidly than the system glucose plus glyceric aldehyde phosphoric acid. The glyceric aldehyde phosphoric acid can also be used to abolish the induction period. There is thus nothing to contradict the supposition that glyceric aldehyde phosphoric acid is formed as an intermediate product.

(2) The rôle of the acetaldehyde in the progress of the esterification consists in the oxidation of the momentary reaction products. One can therefore replace the acetaldehyde fairly well with other reducible systems, for example, methylene blue. Thus, the esterification can be conducted in accordance with equation $\mathrm{B}$, using methylene blue instead of acetaldehyde. In this case, the oxidation product seems to be also phosphoglyceric acid. Therefore, methylene blue can also be used similarly to acetaldehyde as an activator of fermentation. The aldehyde reacts obviously with a nascent triose phosphoric acid produced from the reaction between glucose and hexose di-phosphate. At the same time the aldehyde prevents the rearrangement of the triose phosphoric acid into glycero-phosphoric acid, so that the entire triose phosphoric acid is oxidised to phosphoglyceric acid. Everything gathered together results in the fermentation scheme shown in Table 3 .

Here, in accordance with data obtained from kinetic studies it is necessary to separate the initial period of fermentation from the stationary state. In this case also, fluoride alone inhibits reaction $B$, while iodoacetic acid does not inhibit $\mathrm{B}$, but does inhibit reactions $\mathrm{A}$ and $\mathrm{C}$.
This new scheme will be seen to agree with all known facts. It explains the esterification of the phosphates, the characteristic catalytic rôle of the hexose di-phosphoric acid and the part played by acetaldehyde in determining the initial period. It shows fermentation further as an oxidationreduction process in which most probably the dismutation of two aldehydes, acetaldehyde and glyceric aldehyde phosphoric acid, play the crucial parts. Finally, it brings the carboxylase into the process in an easily conceivable manner. The difference between alcoholic fermentation and lactic acid formation is to be found in the fate of the pyruvic acid. While pyruvic acid in muscle extract is reduced to lactic acid by the glycero-phosphoric

TABLE 3. New fermentation scheme.
Hesose di-phosphoric
+1 Glucose
+2 Phosphoric acid

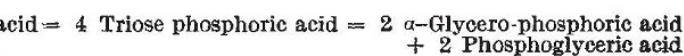
B. 2 Phosphoglyceric acid
$\begin{aligned} 2 \text { Pyruvic acid } & =2 \text { Acetaldehyde } \\ +2 \text { Phosphoric acid } & +2 \text { Carbon lioxide } \\ & +2 \text { Phosphoric acid }\end{aligned}$
StationaRY CONDITION
Acetaldehyde 2 Phosphoric acid
$=2$ Triose phosphoric acid $=2$ Alcohol
+2 Acetaldehyde
+2 Phosphoglyceric acid

acid, in yeast, it is split up into carbon dioxide and acetaldehyde, which acetaldehyde is then reduced. This reduction, however, is not accomplished by the glycero-phosphoric acid, but by some precursor, probably the glyceric aldehyde phosphoric acid. This circumstance determines the peculiar disproportionality of the reaction chain and compels us to set up one equation for the initial period and another for the stationary condition. The periods of induction and rising fermentation are, as well known, not present in lactic acid formation.

The recognition of these facts, which are all more or less connected with the Embden scheme of lactic acid formation, has brought us a good step forward and I think that now a large number of previously known facts may be fitted into a unified picture.

\title{
The British Association at Leicester
}

$\mathrm{O}^{\mathrm{N}}$ the eve of a meeting of the British Association, the members about to converge on the chosen site begin to take a lively interest in its merits and demerits.

A booklet of a hundred pages entitled "A Scientific Survey of Leicester and District", prepared for the Leicester meeting, partly answers this and shows very clearly the inescapable advantages and disadvantages of position revealed in the accounts of the geology and climate; the natural features that result in its flora and fauna; and the development by man of its economic possibilities described under farming and under industries of Leicester. This association of factors and interlocking of cause and effect is well brought out by the editor of the booklet, Dr. P. W. Bryan, in his account of Leicester in its regional setting.

The corporate work of the citizen is described by the Town Clerk in a brief résumé of the rapid increase of activities since the establishment in 1835 of the new municipal body, particularly in relation to trading undertakings. Education, as a very special part of municipal responsibilities, is presented by the director of education, Mr. F. P. Armitage.

These accounts give prominence to the extreme administrative activity and forward thinking which resulted in the reorganising and in particular the re-grouping by 1929 of all the council schools in Leicester, in such a way as to make possible 
educational provision more closely related to individual need and capacity. What may be termed the welfare aspect has been developed pari passu by means of playing fields and by constant remedial help.

The section on men of science in Leicester and Leicestershire cannot fail to be of special interest to members of the British Association and its well-wishers, for it is by workers rather than by facilities-though these have become increasingly necessary for modern work - that science advances.

The late but timely appearance of the new "Flora of Leicestershire and Rutland" by A. R. Horwood and the late Lord Gainsborough (London : Oxford University Press, 35s. net) no doubt accounts for the omission from the section of some, more particularly concerned with this type of work, who would otherwise have found a place.

The flora now hot from the Press is indeed no mere flora but a massive compilation of information about the plants of the district, written to a large extent in the modern ecological and genetical spirit by Mr. Horwood, who was connected with Loicester and its museum for so many years. The introduction alone takes up some three hundred pages and includes not only accounts of the characteristic plant groupings of certain districts but also features of the topography, geology and agriculture.

In the "Scientific Survey" account of men of science connected with Leicester, many worthy names occur, but the most outstanding are those of Alfred Russel Wallace and Henry Walter Bates of Amazon fame. Borm in the first quarter of the nineteenth century, within two years of one another, they early became fast friends. Bates, apprenticed to a hosier, found education and delight in Charnwood Forest, while Alfred Russel Wallace enlivened the tedium of the life of a schoolmaster by the enthusiastic cultivation of the study of botany with the establishment of a herbarium. Fired by Charles Darwin's "Journal of a Naturalist" they went to the Amazon together in 1848, and some years after there appeared Bates's "A Naturalist on the Amazon" and later, Wallace's Linnean contribution paralleling and indeed preceding Charles Darwin's theory of evolution. No greater thing has come out of Leicester.

Altogether the survey presents an interesting and stimulating account of the factors operating in and about Leicester and of the human response which makes it a continually improving city. Visitors will probably be interested in the means which have been taken to secure a good water supply, to dispose of its sewage in spite of the awkward basin shape of the site and to foster the welfare and education of its young citizens. The readers of the booklet, however, may wish that they had been supplied with more information concerning the development of university education and research in this region and all that has come with it during the last decade in the way of exposition and research in the sciences. The University College, in spite of many handicaps, has equipped and sent out students, some of whom were of the highest merit, able to take honourable positions in industry or the services, and it has fostered the spirit of research and been the fons et origo of many publications on pure science and its applications. During this period a record number of ominent scientific workers of rare lecturing capacity have been induced by the College to give freely of their best to Leicester. It is a sign of the trend of modern times and not unfitting in the city of Wallace and of Bates that a large proportion of these ominent investigators have been biologists.

\section{Obituary}

DR. V. H. VELEY, F.R.S.

$\mathrm{D}^{\mathrm{R}}$ R. V. H. VELEY, who died on August 20, aged seventy-seven years, was my tutor from 1896 until 1900 , and during term time $I$ used to seo him at least two evenings a woek in his house in Norham Road, as well as working with him in the laboratory near the Parks about three mornings a week. At that time he had attained his fellowship of the Royal Society, and a considerable reputation, through his paper on the "Hydrate Theory of Solution", which was at the time the subject of controversy, and had been made the subject of partisan feeling by the followers of the ionic dissociation theory of solution which was advocated by Ostwald. We, as Dr. Veley's pupils, had naturally to read both sides of the question, and just as naturally, I think most of us had leanings towards the views of our tutor. In the laboratory, whereas it cannot be said that he was a driver for idle pupils who wished to do as little work as possiblo, thero was no doubt if one did take an interest he was always ready to holp one in difficulties, and he had a very clear style in explaining and teaching.

At one period during the time when I was up, there was a largo quantity of Demerara rum shipped to Great Britain, which, whon let down from $40^{\circ}$ overproof to standard strength, developed what was known commercially as 'cloudiness and floaters'. In some casos this faultiness became almost like a sediment of frog spawn in the rum puncheons. Dr. Voloy, jointly with his wife, investigated this, and they discovered a microorganism which was named by him Coleothrix Methystes (from the Greek for 'drunkard', a rather happy suggestion of Mr. Arthur Sidgwick). It is a remarkable organism insomuch as it is capable of living in alcohol $40^{\circ}$ overproof in an attenuated condition, and whon dilution takes place it is able to increase at such an extraordinary pace that it 